\title{
The Construction of Smart Tourism and Regional Tourism Innovation Development Model
}

\author{
Xiaoli Yan \\ Dalian Vocational \& Technical College, 116035, China
}

Keywords: Smart Tourism; Regional Tourism; Innovation; Development

\begin{abstract}
Combining smart tourism with regional tourism and building a new development model and it is a key way to ensure that China's tourism industry can continue to operate while meeting consumer demand. In order to ensure that the development of this work can meet the expected requirements, this paper will first introduce the connotation of smart tourism, and then analyze the significance of smart tourism and regional tourism innovation development. The last part is aimed at explaining the construction of innovative development mode.
\end{abstract}

\section{Introduction}

With the continuous development of China's society and economy, people pay more and more attention to the way of tourism. For the problems discussed in this article, smart tourism can better meet the needs of tourists and realize intelligence on the basis of the original tourism services, and then optimize and upgrade the traditional tourism industry structure [1]. Under such a background, relevant departments must be able to effectively combine smart tourism with regional tourism, and build a new development model based on this, avoiding the problems of geographical protection and poor tourism environment in traditional tourism. At the same time, the application of smart tourism related concepts in the process of regional tourism development can also bring new ideas to relevant local authorities, ensuring long-term and sustainable development of scenic spots, scenic spots or tourist routes, and contributing to the local economy. Combining the above two points, it is very necessary to study the construction methods of specific innovation development models. This article will be discussed in detail in the following content, in order to provide theoretical reference for relevant units and staff.

\section{Connotation of Smart Tourism}

By definition, smart tourism mainly refers to the modern information technology as the carrier, focusing on the needs of tourists, through the integration of tourism information, and then on the basis of the realization of intelligent tourism services to optimize the traditional tourism industry structure [2]. Combined with this definition, the connotation of smart tourism mainly includes the following points:

\subsection{People-Oriented}

Taking information service as an example, under the traditional tourism mode, visitors can only collect different types of information through different departments, such as distribution of attractions, accommodation information, etc. In the smart tourism, visitors will be able to collect all the required information in one stop. Through the application of the Internet of Things, mobile Internet, etc., the provision of information services will be centered on the location of the tourists, and its targeting will naturally be stronger.

\subsection{Comprehensive Sensing}

Comprehensive sensing mainly refers to the continuous collection of relevant tourist information and tourist feedback information through the installation of imaging equipment in various tourism links, and the timeliness of information will be better guaranteed [3]. Through comprehensive sensing of related technologies and equipment applications, not only the relevant management units 
can more effectively complete the management work in the scenic area through these contents, but also visitors can choose the route under the support of this technology.

\subsection{Self-Innovation}

With the support of computer technology and network technology, enterprises, tourists and governments will be effectively integrated. Enterprises will be better able to grasp the needs of tourists. The government will get more timely feedback from tourists. Visitors can naturally Get a better experience during the tour [4]. Under such a background, government functions will also undergo a certain transformation, assisting relevant units to use modern information technology to maximize the comprehensive value of the region's ecology, culture and economy.

\section{Significance of Smart Tourism and Regional Tourism Innovation Development Model}

\subsection{Provide New Ideas for The Development of Regional Tourism}

Combined with the above, if you can't improve on the traditional travel mode, you will have to face a lot of loss of tourists and economic losses. In this context, smart tourism will provide new ideas for the development of regional tourism. Smart tourism is not only a new form of tourism. For related management units, smart tourism is a new concept of tourism planning. Through the application of intelligent concepts and equipment, the optimization and upgrading of the tourism industry structure can naturally be completed well, and thus can avoid the above problems.

\subsection{Opening Up New Avenues for the Development of Regional Tourism}

In combination with the characteristics of smart tourism itself, the provision of related services is mainly carried out in the form of online through the use of the network. Under such a background, regional tourism can integrate tourism information with the support of the concept of smart tourism. To provide users with a comprehensive service platform. Through the application of this platform, not only tourists can obtain tourist information in time, but also the unfair competition in the tourism market will be more effectively controlled, and the new path will ensure the continuous development of regional tourism.

\section{Construction Method}

\subsection{Based on the Development of The Tourism Industry}

Combined with the characteristics of smart tourism itself, the tourism industry in each region will inevitably be more closely integrated in the subsequent development process, and finally form a complete industrial structure. From this point of view, in the process of development, regional tourism must proceed from the development of the tourism industry, determine the direction of development, and have a long-term development vision to ensure that regional tourism can occupy a place in the market. For such requirements, the relevant management units should effectively link with the surrounding areas with reference to the following models: Although the development of regional tourism is to improve the development of tourism industry in a certain region as the ultimate goal, it is to regard a specific region as the center. At the same time, the relevant management departments should be able to effectively link them with the attractions of the surrounding provinces and cities, realize the sharing of resources, and achieve mutual promotion. Under such a development model, the development of local tourism can naturally be better protected. Taking Qinhuangdao as an example, through effective communication with Beijing, Tangshan and other places, the interaction between cities must be more frequent, and the economic interaction can also be promoted and promoted among different regions to ensure that the construction of regional tourism development innovation model can achieve the expected result.

\subsection{Clear Construction Goals}

The construction goal is the core of the overall smart tourism and regional tourism development 
process. For this, all construction work and design work should be completed under the guidance of construction goals to ensure the development of smart tourism and regional tourism and serve local development goals better. In the process of determining the construction goals, the following points can be combined to ensure the scientific and rationality of this goal: (1)To meet the tourist needs of tourists. This is the core concept of smart tourism. Therefore, this should be included in the specific development and construction goals to ensure that all construction work in the region can be carried out around the needs of tourists. Under such a background, tourists' satisfaction with scenic spots is constantly improving, and the development of regional tourism can naturally be guaranteed on the original basis. (2)Realize the docking of tourism public services and public management. The regional tourism management system not only includes the management of tourists, but also the management of each enterprise. If the problems such as vicious competition between these enterprises are not effectively controlled, then tourists naturally cannot get a high-quality service experience. Therefore, relevant management departments should be able to combine tourism public services with public management, and manage all objects within the scope of control to achieve the development goals of smart tourism.

\subsection{Efficiently Complete the Process of Innovation Integration}

Innovation integration mainly refers to the integration between the introduction of smart tourism and traditional human factors. The construction of most tourist attractions in China is related to local humanities and history, and whether the introduction of modern technology will affect the perception of tourists is the relevant units must consider the issue. For the development of this work, the management unit should be able to complete the innovation integration process by combining the following points: (1)Combine modern information technology to develop a characteristic tourism route. Data analysis and other technologies can assist relevant management units to conduct in-depth analysis of tourists' preferences. Through the application of these technologies, management units can improve existing travel routes and processes to ensure that tourism services are more targeted. (2) Introduce smart tourism in combination with the objective status of the region. In order to ensure that smart tourism can play an effective role, relevant personnel should be able to combine the modern information technology contained in smart tourism with local human resources in combination with the location of the attraction to provide visitors with both material and spiritual enjoyment.

\section{Conclusion}

In summary, the construction of smart tourism and regional tourism innovation development model should start from three aspects: the development of the tourism industry, the clear construction goals, and the efficient completion of the innovation integration process. In the follow-up development process, the relevant management departments should conduct further research on the needs of tourists, and combine the specific research results with the concept of smart tourism to improve the regional tourism development methods to ensure long-term and stable regional tourism. The development has brought positive positive effects to the local economy and other aspects.

\section{References}

[1] Weng Gangmin, Li Weijin. Construction of Innovative Development Model of Smart Tourism and Regional Tourism - - Taking Qinhuangdao as an Example[J]. Urban Development Research, 2014, (5).

[2] Zhang Guanghai, Ruan Chuanxiang. Research on Regional Cooperation of Smart Tourism in Northeast Asia[J]. Northeast Asian Economic Research, 2018, (3).

[3] Wu Juan.Discussion on the Regional Tourism Cooperation Path of Xijiang Economic Belt in Guangxi--Based on the Perspective of Smart Tourism[J].Journal of Hebei Tourism Vocational 
College,2015,(3).

[4] Bai Xiujun, Li Ping. Research on the Construction of Regional Smart Tourism Service Platform - - Taking Zaozhuang City as an Example[J]. Tourism World - Tourism Development Research, 2018, (4). 